\title{
-Original Articles-
}

\section{The self-renewal process of murine hemopoietic stem cells supported by interleukin-3 and the synergistic factors and the probability of its occurrence}

\author{
Katsumi Kaneko ${ }^{1)}$ and Kenji Ikebuchi ${ }^{2)}$ \\ "Department of Dermatology, Nippon Medical School \\ ${ }^{2}$ Department of Blood Transfusion, Institute of Medical Science, University of Tokyo
}

\begin{abstract}
Summary
By use of the in vitro murine blast cell colony (Bl) assay system, Bl-constituting cells supported by interleukin-3 (IL-3), IL-3 + interleukin-6 (IL-6), IL-3 + granulocyte colonystimulating factor (G-CSF) and IL-3 + interleukin-1 (IL-1) were replated and the frequencies of secondary (2nd) granulocyte/erythrocyte/macrophage/megakaryocyte (GEMM) colony and $\mathrm{Bl}$ progenitors were examined. According to the statistical method reported by Nakahata et al, the $\mathrm{p}$ values for the hemopoietic stem cells to self-renew were calculated and all cytokine groups produced similar $\mathrm{p}$ values ranging between 0.576 and 0.596 . Further studies using IL-3-supported and IL-3 + G-CSF-supported Bl showed that the 2nd Bl progenitors could be produced even when there were more than 150 primary Bl-constituting cells per colony in the case of IL-3 + G-CSF, but no 2nd Bl progenitors were found in the case of IL3. Their appearance was limited within the smaller primary $\mathrm{Bl}$ when supported by IL-3. Again there was a difference in the net product number of 2 nd $\mathrm{Bl}$ progenitors, that is, the addition of G-CSF to the primary culture could produce around double the number of 2nd $\mathrm{Bl}$ progenitors. These data led us to hypothesize that synergistic factors could not modify the self-renewal probability, but maintained the self-renewal process for a longer period, in other words, for several cellular divisions.
\end{abstract}

Key words: hemopoietic stem cell, self-renew, blast cell colony, interleukin-3 (IL-3), granulocyte colony-stimulating factor (G-CSF)

\section{Introduction}

A number of hemopoietic cytokines have been identified, and molecular biology techniques can produce large amounts of cytokines, making it possible to use these cytokines for in vivo administrations. Erythropoietin (Epo) and granulocyte colony-stimulating factor (G-CSF) have already been used clinically on several anemic and neutropenic patients and their therapeutic value has been established. A lot of scientists and clinicians have been interested in the cytokines regulating hemopoietic stem cells, and synergistic factors such as

Correspondence to Katsumi Kaneko, Department of Dermatology, Nippon Medical School Hospital, 1-1-5 Sendagi, Bunkyo-ku, Tokyo 113, Japan 
interleukin-6 (IL-6), G-CSF, interleukin-1 (IL-1), interleukin-11 (IL-11). The stem cell factor (SCF) has also been energetically investigated to expand stem cells both in vitro and in vivo $^{1 \sim 4)}$.

The hemopoietic stem cells are few in number, and are present in the hemopoietic organs; they possess unique biological characteristics such as multipotentiality, dormancy in the cell cycle and self-renewability ${ }^{5,6}$. Nakahata et al have studied their characteristics closely by use of their established $\mathrm{Bl}$ assay system, and have proposed a so-called stochastic model of their proliferation and differentiation processes ${ }^{7}$. By use of replating experiments with Bl-constituting cells, they also calculated the $\mathrm{p}$ value for stem cells to self-renew and noted it to be around $0.589^{8}$. How to expand the hemopoietic stem cells is a difficult question and it is important first to understand the biological events which occur during the self-renewal process.

In this study, we tried to find out whether the hemopoietic cytokines, especially so-called synergistic factors, could modify the self-renewal process of the hemopoietic stem cells.

\section{Materials and Methods}

(1) Cell preparations

Eight to 12-week-old female BDF1 mice were purchased from Japan SLC (Shizuoka, Japan). 5-FU (Kyowa Hakko Kogyo, Tokyo, Japan) at $150 \mathrm{mg} / \mathrm{kg}$ body weight was administered through the tail vein 4 days before the sacrifice of the mice. Spleen cells were then harvested and single cell suspensions were prepared from the pooled spleens of three mice.

(2) Growth factors and clonal cell culture

Silkworm-derived recombinant murine IL-3 with a specific activity of $2.8 \times 10^{8} \mathrm{U} / \mathrm{mg}$ protein was donated by Dr. A. Miyajima (DNAX, Palo Alto, CA) ${ }^{9}$. Recombinant human IL-6 with a specific activity of $5 \times 10^{6} \mathrm{U} / \mathrm{mg}$ protein was donated by Ajinomoto Co. Inc. (Kawasaki, Japan) ${ }^{10)}$. Purified recombinant human G-CSF expressed in CHO cells was a gift from Chugai Pharmaceutical Co. (Tokyo, Japan). Recombinant human IL- $1 \beta$ expressed in E. coli was generously donated by Otsuka Pharmaceutical Co. (Osaka, Japan). CHO-derived human recombinant erythropoietin (Epo) was provided by Chugai Pharmaceutical Co. WEHI-3 conditioned medium (WEHI-3 CM) was a gift from Dr. T. Suzuki (Kirin Brewery Co., Gunma, Japan). The concentrations of the factors in this study were as follows: IL-3, 200 $\mathrm{U} / \mathrm{m} l$; IL-6, $100 \mathrm{ng} / \mathrm{m} l$; G-CSF, $10 \mathrm{ng} / \mathrm{m} l ; \mathrm{IL}-1 \beta, 2 \mathrm{ng} / \mathrm{m} l$; Epo, $2 \mathrm{U} / \mathrm{m} l$.

Methylcellulose culture was performed in $35 \mathrm{~mm}$ Falcon suspension culture dishes (Beckton Dickinson Labware, Lincoln Park, NJ). One $\mathrm{m} l$ of culture contained $1 \times 10^{6}$ spleen cells of 5-FU treated mice, alpha-medium (Sigma Chemical Co., St. Louis, MO), 1.2\% 1500 cps methylcellulose (Wako Pure Chemical Industries, Osaka, Japan), 30\% fetal calf serum (FCS) (Hyclone Laboratories, Inc., Logan, UT), 1\% deionized fraction $\mathrm{V}$ bovine serum albumin (BSA) (Sigma), $1 \times 10^{-4} \mathrm{~mol} / \mathrm{L} 2$-mercaptoethanol (Sigma) and hemopoietic factors. Dishes were incubated at $37^{\circ} \mathrm{C}$ in a humidified atmosphere flashed with $5 \% \mathrm{CO}_{2}$. Colony types were determined on the specified culture day by in situ observation with an inverted microscope according to the criteria described previously ${ }^{7}$. Abbreviations for colony types 
are as follows: GM, granulocyte/macrophage; GEMM, granulocyte/erythrocyte/macrophage/megakaryocyte; and $\mathrm{Bl}$, blast cell colonies.

(3) Replating experiments

On day 5-10 of culture, small Bls were individually lifted with an Eppendort micropipette, and suspended in $0.1 \mathrm{~m} l$ alph-medium. After gentle pipetting samples were added individually to $0.9 \mathrm{~m} l$ methylcellulose culture dishes containing WEHl-3 CM $(10 \% \mathrm{v} / \mathrm{v})$ and Epo. The dishes were then incubated at $37^{\circ} \mathrm{C}$ in a humidified atmosphere flashed with $5 \% \mathrm{CO}_{2}$. Colony types were determined in the same manner as in the primary cultures.

(4) Calculation of self-renewal probability

Multipotential $\mathrm{Bl}$ were grouped into two ; one produced both 2nd GEMM and $\mathrm{Bl}$ and the other produced only 2nd GEMM without $\mathrm{Bl}$. If the $\mathrm{Bl}$ progenitor chose the self-renewal process, a "birth" process, the Bl-constituting cells should contain the 2nd Bl progenitors. On the contrary, if the stem cell chose a "death" process, 2nd Bl progenitors could no longer be produced. The latter choice was also called the "extinction" process and the extinction probability, designated as "s", was calculated as the ratio of multipotential $\mathrm{Bl}$ without 2nd $\mathrm{Bl}$ progenitors per all multipotential Bl. Following Harris' procedure ${ }^{11)}$, the pvalue, the probability that a $\mathrm{Bl}$ progenitor at any given generation produces a new identical progenitor cell was calculated as follows: $p=(1-\sqrt{s}) /(1-s)$.

\section{Results}

1. Replating experiments with Bl supported by IL-3, IL-3 + IL-6, IL-3 + G-CSF, IL-3 + IL-1 $\beta$

Spleen cells of 5-FU-treated mice were cultured in the presence of IL-3, IL-3 + IL-6, IL$3+$ G-CSF, and IL-3 + IL- $1 \beta$. Since spleen cells usually contained relatively higher number of multipotential progenitors than bone marrow cells did. From day 5 to 10 of culture, new $\mathrm{Bl}$ with less than 150 cells per colony appeared daily and were lifted by Eppendorf micropipette, and replated. In another experiments, morphological confirmation of constituent cells of Bl had already performed, and all of these cells revealed immature nuclei and absence of cytoplasmic differentiation. Secondary colonies were counted on day 12. Data from replating experiments of primary $\mathrm{Bl}$ are shown in Table 1. The constituent cells of $\mathrm{B} 1$ possessed the same biological characteristics as the hemopoietic progenitors and could make secondary colonies in the methylcellulose culture. Among them, most colonies were oligopotential GM colonies and multipotential GEMM colonies constituted of 5,000-100,000 cells. However, some colonies were a diffuse type and contained a small number of cells, ranging between 30 and 150, which looked like immature blast cells. Higher than $100 \%$ replating efficiencies seen in some colonies are probably due to technical errors in estimation of cell numbers.

Since the primary $\mathrm{Bl}$ were derived from 5-FU-resistant, dormant hemopoietic stem cells, the $2 \mathrm{nd} \mathrm{Bl}$ that were witnessed in this experiment were probably derived from the dormant stem cells produced by the primary stem cells after cell divisions. Nakahata and Ogawa ${ }^{7)}$ reported the presence of both the primary $\mathrm{Bl}$ and the 2nd $\mathrm{Bl}$, and the mechanism of the 
Table 1 Results of replating experiments on blast cell colonies

(1) IL-3

\begin{tabular}{|c|c|c|c|c|c|}
\hline \multirow{2}{*}{$\begin{array}{c}\text { Blast cell } \\
\text { colony size }\end{array}$} & \multicolumn{4}{|c|}{ Number of secondary colonies } & \multirow{2}{*}{$\begin{array}{l}\text { Replating } \\
\text { efficiency }(\%)\end{array}$} \\
\hline & GM & GEMM & $\mathrm{bl}$ & Total & \\
\hline 55 & 12 & 3 & & 15 & 27.3 \\
\hline 35 & 14 & 2 & 2 & 18 & 51.4 \\
\hline 30 & 21 & 1 & & 22 & 73.3 \\
\hline 61 & 40 & 8 & & 48 & 78.7 \\
\hline 46 & 23 & 10 & & 33 & 71.7 \\
\hline 44 & 21 & 5 & & 26 & 59.1 \\
\hline 41 & 24 & 6 & & 30 & 73.2 \\
\hline 48 & 15 & 3 & & 18 & 37.5 \\
\hline 64 & 32 & 11 & 1 & 44 & 68.8 \\
\hline 105 & 33 & 4 & & 37 & 35.2 \\
\hline 51 & 21 & 6 & 2 & 29 & 56.9 \\
\hline 48 & 10 & 3 & 2 & 15 & 31.3 \\
\hline 44 & 12 & 11 & 3 & 26 & 59.1 \\
\hline 48 & 23 & 5 & & 28 & 58.3 \\
\hline 30 & 5 & 2 & & 7 & 23.3 \\
\hline 55 & 9 & 4 & 1 & 14 & 25.5 \\
\hline 30 & 10 & 3 & 3 & 16 & 53.3 \\
\hline 71 & 9 & 8 & 9 & 26 & 36.6 \\
\hline 86 & 19 & 3 & & 22 & 25.6 \\
\hline 116 & 35 & 3 & & 38 & 32.8 \\
\hline 100 & 43 & 2 & 2 & 47 & 47.0 \\
\hline 32 & 14 & 4 & & 18 & 56.3 \\
\hline 48 & & 3 & 3 & 6 & 12.5 \\
\hline 30 & 15 & 2 & & 17 & 56.7 \\
\hline 48 & 14 & 2 & & 16 & 33.3 \\
\hline 61 & 27 & 2 & 2 & 31 & 50.8 \\
\hline 86 & 23 & 5 & & 28 & 32.6 \\
\hline 30 & 1 & 7 & 7 & 15 & 50.0 \\
\hline 30 & & 1 & & 1 & 3.3 \\
\hline 97 & 31 & 2 & & 33 & 34.0 \\
\hline 30 & & 2 & 4 & 6 & 20.0 \\
\hline 89 & 22 & 6 & 4 & 32 & 36.0 \\
\hline 68 & 7 & 2 & 7 & 16 & 23.5 \\
\hline 31 & 7 & 2 & 2 & 11 & 35.5 \\
\hline 40 & 8 & 2 & 3 & 13 & 32.5 \\
\hline 120 & 64 & 8 & 4 & 76 & 63.3 \\
\hline 87 & 18 & 7 & 2 & 27 & 31.0 \\
\hline 72 & 13 & 3 & 1 & 17 & 23.6 \\
\hline 82 & 39 & 6 & 2 & 47 & 57.3 \\
\hline \multicolumn{6}{|c|}{ (3) $\mathrm{IL} \cdot 3+\mathrm{G} \cdot \mathrm{CSF}$} \\
\hline \multirow{2}{*}{$\begin{array}{c}\text { Blast cell } \\
\text { colony size }\end{array}$} & \multicolumn{4}{|c|}{ Number of secondary colonies } & Replating \\
\hline & GM & GEMM & $\mathrm{bl}$ & Total & efficiency $(\%)$ \\
\hline 32 & 21 & 9 & 3 & 33 & 103.1 \\
\hline 42 & 23 & 2 & & 25 & 59.5 \\
\hline 34 & 20 & 5 & & 25 & 73.5 \\
\hline 41 & 25 & 2 & & 27 & 65.9 \\
\hline 42 & 35 & 7 & & 42 & 100.0 \\
\hline 51 & 31 & 9 & & 40 & 78.4 \\
\hline 45 & 26 & 1 & & 27 & 60.0 \\
\hline 42 & 19 & 17 & 8 & 44 & 104.8 \\
\hline 41 & 1 & 1 & & 2 & 4.9 \\
\hline 51 & 24 & 10 & 2 & 36 & 70.6 \\
\hline 35 & 11 & 3 & & 14 & 40.0 \\
\hline 90 & 56 & 4 & 2 & 62 & 68.9 \\
\hline 39 & 12 & 9 & 6 & 27 & 69.2 \\
\hline 38 & 9 & 3 & 2 & 14 & 36.8 \\
\hline 79 & 33 & 6 & 1 & 40 & 50.6 \\
\hline 55 & 32 & 3 & & 35 & 63.6 \\
\hline 50 & 10 & 4 & 2 & 16 & 32.0 \\
\hline 41 & 36 & 2 & 1 & 39 & 95.1 \\
\hline 134 & 87 & 12 & 2 & 101 & 75.4 \\
\hline 44 & 24 & 16 & 3 & 43 & 97.7 \\
\hline 109 & 38 & 2 & & 40 & 36.7 \\
\hline 105 & 30 & 2 & 1 & 33 & 31.4 \\
\hline 36 & 9 & 6 & & 15 & 41.7 \\
\hline 30 & 17 & 1 & & 18 & 60.0 \\
\hline 95 & 10 & 1 & & 11 & 11.6 \\
\hline 87 & 45 & 2 & 2 & 49 & 56.3 \\
\hline 94 & 46 & 3 & & 49 & 52.1 \\
\hline 52 & 42 & 1 & & 43 & 82.7 \\
\hline 63 & 28 & 5 & 1 & 34 & 54.0 \\
\hline 38 & 11 & 6 & 15 & 32 & 84.2 \\
\hline 100 & 69 & 8 & 9 & 86 & 86.0 \\
\hline 77 & 30 & 5 & & 35 & 45.5 \\
\hline 43 & 21 & 8 & & 29 & 67.4 \\
\hline 73 & 73 & 11 & & 84 & 115.1 \\
\hline 64 & 79 & 1 & & 80 & 125.0 \\
\hline
\end{tabular}

\begin{tabular}{|c|c|c|c|c|c|}
\hline \multirow{2}{*}{$\begin{array}{l}\text { Blast cell } \\
\text { colony size }\end{array}$} & \multicolumn{4}{|c|}{ Number of secondary colonies } & \multirow{2}{*}{$\begin{array}{c}\text { Replating } \\
\text { efficiency }(\%)\end{array}$} \\
\hline & GM & GEMM & bl & Total & \\
\hline 47 & 2 & 1 & & 3 & 6.4 \\
\hline 33 & 10 & 1 & & 11 & 33.3 \\
\hline 45 & 26 & 6 & 1 & 33 & 73.3 \\
\hline 68 & 43 & 4 & 1 & 48 & 70.6 \\
\hline 45 & 14 & 2 & & 16 & 35.6 \\
\hline 30 & 4 & 1 & & 5 & 16.7 \\
\hline 36 & 12 & 4 & 4 & 20 & 55.6 \\
\hline 65 & 35 & 3 & & 38 & 58.5 \\
\hline 38 & 11 & 3 & 2 & 16 & 42.1 \\
\hline 41 & 2 & 2 & & 4 & 9.8 \\
\hline 44 & 19 & 7 & & 26 & 59.1 \\
\hline 84 & 72 & 9 & 1 & 82 & 97.6 \\
\hline 87 & 27 & 2 & & 29 & 33.3 \\
\hline 77 & 49 & 6 & & 55 & 71.4 \\
\hline 72 & 48 & 6 & 4 & 58 & 80.6 \\
\hline 60 & 30 & 3 & 4 & 37 & 61.7 \\
\hline 78 & 25 & 14 & & 39 & 50.0 \\
\hline 81 & 43 & 1 & 1 & 45 & 55.6 \\
\hline 125 & 44 & 2 & & 46 & 36.8 \\
\hline 100 & 48 & 14 & & 62 & 62.0 \\
\hline 148 & 43 & 2 & 1 & 46 & 31.1 \\
\hline 52 & 22 & 11 & 2 & 35 & 67.3 \\
\hline 76 & 100 & 10 & & 110 & 144.7 \\
\hline 46 & 11 & 5 & 5 & 21 & 45.7 \\
\hline 30 & 15 & 2 & 2 & 19 & 63.3 \\
\hline 68 & 10 & 14 & 14 & 38 & 55.9 \\
\hline 61 & 24 & 16 & 3 & 43 & 70.5 \\
\hline 98 & 57 & 13 & & 70 & 71.4 \\
\hline 79 & 3 & 2 & 7 & 12 & 15.2 \\
\hline 43 & 18 & 3 & 1 & 22 & 51.2 \\
\hline 126 & 89 & 9 & & 98 & 77.8 \\
\hline 120 & 54 & 8 & 12 & 74 & 61.7 \\
\hline 100 & 66 & 6 & & 72 & 72.0 \\
\hline 62 & 44 & 12 & 17 & 73 & 117.7 \\
\hline 100 & 97 & 2 & & 99 & 99.0 \\
\hline 100 & 89 & 10 & & 99 & 99.0 \\
\hline 30 & 6 & 2 & 3 & 11 & 36.7 \\
\hline 116 & 41 & 2 & & 43 & 37.1 \\
\hline 120 & 74 & 7 & 3 & 84 & 70.0 \\
\hline 40 & 11 & 3 & 2 & 16 & 40.0 \\
\hline 36 & 51 & 7 & & 58 & 161.1 \\
\hline 36 & 9 & 1 & & 10 & 27.8 \\
\hline 116 & 126 & 10 & & 136 & 117.2 \\
\hline 76 & 23 & 9 & 2 & 34 & 44.7 \\
\hline
\end{tabular}

\begin{tabular}{|c|c|c|c|c|c|}
\hline \multirow{2}{*}{$\begin{array}{l}\text { Blast cell } \\
\text { colony size }\end{array}$} & \multicolumn{4}{|c|}{ Number of secondary colonies } & \multirow{2}{*}{$\begin{array}{c}\text { Replating } \\
\text { efficiency }(\%)\end{array}$} \\
\hline & GM & GEMM & b] & Total & \\
\hline 34 & 13 & 5 & & 18 & 52.9 \\
\hline 71 & 38 & 5 & 1 & 44 & 62.0 \\
\hline 47 & 25 & 4 & & 29 & 61.7 \\
\hline 35 & 9 & 7 & 4 & 20 & 57.1 \\
\hline 37 & 12 & 1 & $i$ & 14 & 37.8 \\
\hline 40 & 12 & 3 & & 15 & 37.5 \\
\hline 31 & 7 & 1 & 1 & 9 & 29.0 \\
\hline 14 & 3 & 1 & & 4 & 28.6 \\
\hline 35 & 10 & 2 & & 12 & 34.3 \\
\hline 48 & 24 & 5 & & 29 & 60.4 \\
\hline 46 & 24 & 8 & 3 & 35 & 76.1 \\
\hline 83 & 24 & 8 & & 32 & 38.6 \\
\hline 37 & 19 & 2 & & 21 & 56.8 \\
\hline 31 & & 1 & 1 & 2 & 6.5 \\
\hline 36 & 1 & 1 & 1 & 3 & 8.3 \\
\hline 46 & 11 & 1 & & 12 & 26.1 \\
\hline 56 & 19 & 6 & 2 & 27 & 48.2 \\
\hline 61 & 24 & 4 & & 28 & 45.9 \\
\hline 49 & 31 & 11 & & 42 & 85.7 \\
\hline 31 & 3 & 4 & 2 & 9 & 29.0 \\
\hline 74 & 40 & 6 & 2 & 48 & 64.9 \\
\hline 64 & 30 & 2 & & 32 & 50.0 \\
\hline 42 & 10 & 8 & 7 & 25 & 59.5 \\
\hline 96 & 55 & 4 & 5 & 64 & 66.7 \\
\hline 70 & 7 & 8 & 1 & 16 & 22.9 \\
\hline 108 & 54 & 11 & 8 & 73 & 67.6 \\
\hline 70 & 24 & 6 & & 30 & 42.9 \\
\hline 77 & 30 & 4 & & 34 & 44.2 \\
\hline 54 & 15 & 3 & 4 & 22 & 40.7 \\
\hline 71 & 2 & 1 & & 3 & 4.2 \\
\hline 42 & 9 & 13 & 12 & 34 & 81.0 \\
\hline 30 & 8 & 3 & 2 & 13 & 43.3 \\
\hline 30 & 15 & 5 & & 20 & 66.7 \\
\hline 72 & 48 & 10 & 1 & 59 & 81.9 \\
\hline
\end{tabular}
59

81.9

Spleen cells of 5 -FU treated mice, $1 \times 10^{6} / \mathrm{m} l$, were cultured in the presence of IL-3, IL-3+IL-6, IL-3+G-CSF and IL-3+IL-1 $\beta$. From day 5 to day 10 , newly appearing BI, whose constituting cells were ranged between 30 and 150 , were picked, and then replated in the presence of WEHI-3 CM and Epo. 
Table 2 Comparison of self-renewal capacity of blast cell colonies supported by IL-3, IL3 plus IL-6, IL-3 plus G-CSF and IL-3 plus IL-1 $\beta$

\begin{tabular}{l|ccc}
\hline Stimulus & $\begin{array}{c}\text { Blast cell } \\
\text { colonies with } \\
\text { secondary } \\
\text { GEMM } \\
\text { colonies }\end{array}$ & $\begin{array}{c}\text { Blast cell } \\
\text { colonies with } \\
\text { secondary } \\
\text { GEMM } \text { and } \\
\text { blast cell } \\
\text { colonies }\end{array}$ & P value \\
\hline IL-3 & 39 & 21 & 0.5955 \\
IL-3+IL-6 & 44 & 22 & 0.5858 \\
IL-3+ G-CSF & 35 & 16 & 0.5758 \\
IL-3+IL-1 $\beta$ & 34 & 18 & 0.5931 \\
\hline
\end{tabular}

On day 12 of the secondary culture, secondary colony types including GEMM and $\mathrm{BI}$ were analyzed. According to the formula shown in "Materials and Methods", the $\mathrm{p}$ values and self-renewal probabilities were calculated in each group.

Table 3 Comparison of self-renewal capacity of blast cell colonies supported by IL-3 and IL-3 plus G-CSF

\begin{tabular}{|c|c|c|c|c|c|c|c|c|c|c|c|c|}
\hline & \multicolumn{9}{|c|}{ Blast cell colony size $(\mathrm{X})$} & \multirow{2}{*}{\multicolumn{3}{|c|}{ Total }} \\
\hline & \multicolumn{3}{|c|}{$30 \leqq X<100$} & \multicolumn{3}{|c|}{$100 \leqq X<200$} & \multicolumn{3}{|c|}{$200 \leqq X<400$} & & & \\
\hline & A & $\mathrm{B}$ & $P$ value & A & B & $P$ value & A & B & $P$ value & A & $\mathrm{B}$ & $P$ value \\
\hline IL-3 & 58 & 27 & 0.5777 & 39 & 6 & 0.5209 & 16 & 0 & not culculated & 113 & 33 & 0.5432 \\
\hline $\mathrm{IL}-3+\mathrm{G}-\mathrm{CSF}$ & 48 & 23 & 0.5808 & 33 & 8 & 0.5346 & 23 & 8 & 0.5532 & 104 & 39 & 0.5584 \\
\hline
\end{tabular}

BI were supported by IL-3 and IL-3+G-CSF. New BI, which appeared daily, were picked, and then replated.

A : Blast cell colonies with secondary GEMM colonies, B : Blast cell colonies with secondary GEMM and blast cell colonies.

production of the 2nd $\mathrm{Bl}$ was ascribed to the self-renewal characteristic of stem cells. According to their calculation formula of the probabilities of self-renewal, $p$ values were calculated (Table 2). These values were similar to the 0.589 that had been reported by Nakahata et $\mathrm{al}^{8}$, whose work was done using the combination of pokeweed mitogenstimulated spleen cell-conditioned medium (PWM-SCM) + Epo as cytokines. The addition of the so-called synergistic factors for dormant stem cells did not remarkably modify the self-renewal probabilities of the $\mathrm{Bl}$ progenitors.

\section{2nd Bl progenitor production}

As we described previously ${ }^{12 \sim 14)}$, the synergistic factors such as IL-6, G-CSF and IL-1 could shorten the $G_{0}$ periods of dormant hemopoietic stem cells and enhanced the $\mathrm{Bl}$ formation in the earlier period of the culture. Also we reported that the synergistic factors could increase the frequencies of GEMM progenitor cells in constituting cells of $\mathrm{Bl}^{14}$. The true mechanism of this phenomenon was unclear, but there is a possibility that the synergistic factors might increase the 2nd dormant blast cells, thus producing a higher number of multipotential GEMM progenitors during the $\mathrm{Bl}$ formation. In order to show that possibility, 


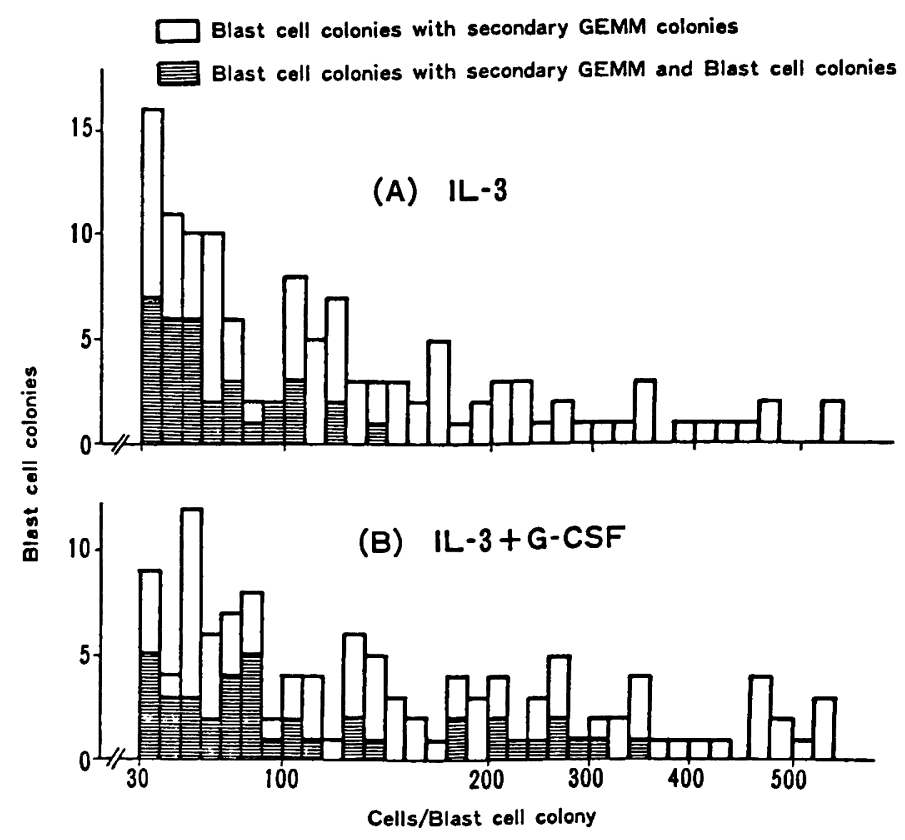

Fig. 1 Size distributions of multipotential blast cell colonies with or without secondary blast cell colony progenitors

Spleen cells of 5 -FU treated mice, $1 \times 10^{6} / \mathrm{m} l$, were cultured in the presence of IL-3 and IL-3 + G-CSF. From day 5 to day 10, newly appearing $\mathrm{Bl}$ were picked, and then replated in the presence of WEHI-3 $\mathrm{CM}$ and Epo.

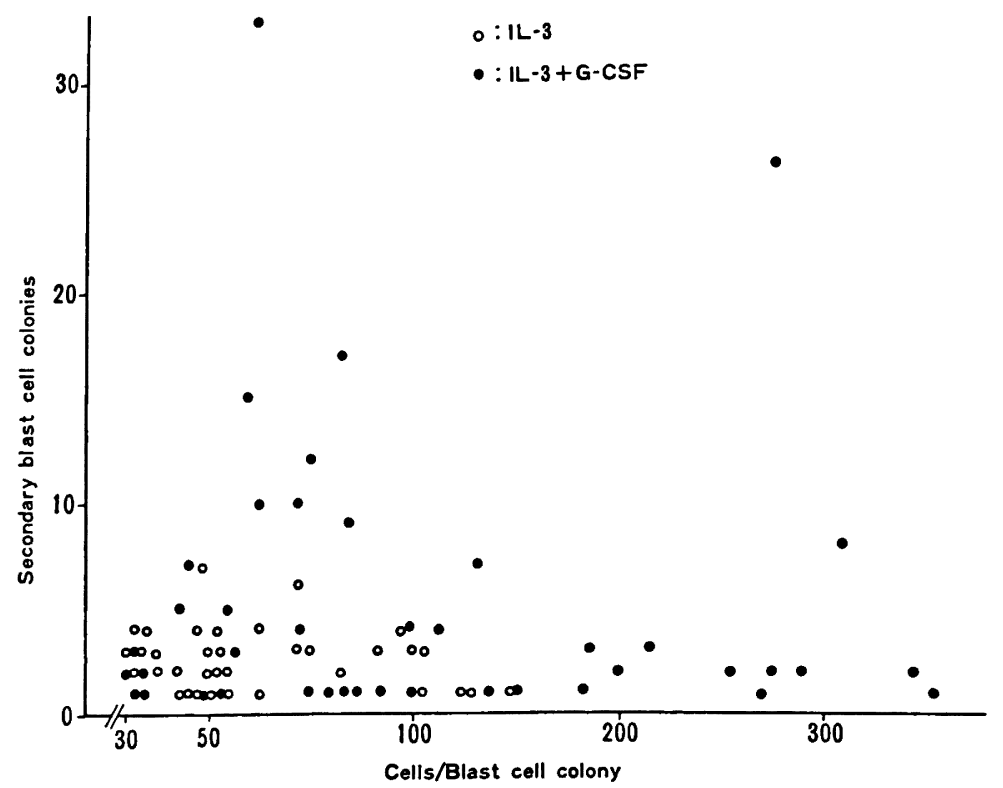

Fig. 2 Productive number of secondary blast cell colony progenitors Spleen cells of $5 \cdot \mathrm{FU}$ treated mice, $1 \times 10^{6} / \mathrm{m} l$, were cultured in the presence of IL-3 and IL-3 + G.CSF. From day 5 to day 10 , newly appearing $\mathrm{Bl}$ were picked,and then replated in the presence of WEHI-3 $\mathrm{CM}$ and Epo. 
Table 4 Comparison of frequency of secondary blast cell colonies in the presence of IL-3 and IL-3 plus G-CSF

\begin{tabular}{|c|c|c|}
\hline \multirow{2}{*}{$\begin{array}{l}\text { Blast cell } \\
\text { colony size }\end{array}$} & \multicolumn{2}{|c|}{$\begin{array}{l}\text { Secondary blast cell colonies/Blast cell } \\
\text { colony with secondary GEMM colonies }\end{array}$} \\
\hline & IL-3 & $\mathrm{IL} \cdot 3+\mathrm{G} \cdot \mathrm{CSF}$ \\
\hline $30 \leqq$ size $\leqq 100$ & 1.63 & 2.96 \\
\hline $100<$ size & 0.17 & 1.10 \\
\hline Total & 0.90 & 1.93 \\
\hline
\end{tabular}

Absolute number of $2 \mathrm{nd} \mathrm{Bl}$ progenitors was divided by the number of primary multipotential $\mathrm{Bl}$.

$\mathrm{Bl}$ were grown in the presence of IL-3 and IL-3 + G-CSF from the spleen cells of 5-FU. treated mice. $\mathrm{Bl}$ were found daily, and were picked up and replated in the secondary culture. Table 3 shows the frequencies of 2nd GEMM progenitors in the $\mathrm{Bl}$ constituting cells. Both the absolute number of the 2nd GEMM progenitors and the percentages of GEMM progenitors in Bl-forming cells were higher in the group supported by the combination of IL-3 and G-CSF than in that supported by IL-3 alone, independent of the $\mathrm{Bl}$ sizes.

The size distributions of the multipotential Bl are shown in Fig. 1. There was a tendency for the constituting cells in IL-3-supported $\mathrm{Bl}$ not to contain 2nd $\mathrm{Bl}$ progenitors when they grew in number to more than 150 cells. Comparatively, the combination of IL-3 and G-CSF kept the colony-constituting cells immature and supported larger $\mathrm{Bl}$ formations with the ability to produce 2 nd $\mathrm{Bl}$ progenitors.

As shown in Fig. 2, IL-3-supported $\mathrm{Bl}$ usually produced 1 to 4 2nd $\mathrm{Bl}$ progenitors and 7 at most; however, IL-3 + G-CSF-supported Bl sometimes produced more than 5 2nd $\mathrm{Bl}$ progenitors. The total number of 2 nd $\mathrm{Bl}$ progenitors divided by that of the initial multipotential $\mathrm{Bl}$ showed how many 2nd stem cells were produced by one initial stem cell (Table 4). The numbers were different among the cytokine groups and among the sizes of primary $\mathrm{Bl}$, but there was a tendency for $\mathrm{Bl}$ forming cells supported by the combinations of IL-3 and G-CSF to produce higher number of 2 nd stem cells reaching around 2 in total.

\section{Discussion}

The hemopoietic stem cells possess biologically important characteristics, such as multipotentiality, dormancy in the cell cycle and a self-renewal capacity. A lot of research has focused on these characteristics and the influence of cytokines. Nakahata et al ${ }^{8)}$ developed an in vitro $\mathrm{Bl}$ formation system and using this $\mathrm{Bl}$ assay they succeeded in calculating the self-renewal probability of the murine hemopoietic stem cells, which was found to be 0.589 .

Recently several cytokines have been introduced and some of them were found to have some influence on the hemopoietic stem cells, such as shortening the $G_{0}$ phase of the cell cycle and expanding them both in vitro and in vivo. The synergistic factors like IL- $6^{12,15)}$, G-CSF ${ }^{13)}$, IL-1 ${ }^{14)}$, IL-11 ${ }^{16)}$ and $\mathrm{SCF}^{17,18)}$ enhanced the IL-3-dependent proliferation of the 
hemopoietic stem cells and the mechanism was ascribed to the shortening of the $\mathrm{G}_{0}$ phase. We found that these synergistic factors produced $\mathrm{Bl}$ with a higher number of 2nd multipotential GEMM progenitors. The mechanism was unclear, but there remains the possibility that those synergistic factors affect their self-renewal process, resulting in a higher production of 2nd $\mathrm{Bl}$ progenitors and GEMM progenitors.

In this paper, we examined the replating experiments of the Bl-constituting cells and calculated the probability of self-renewal, according to the protocol reported by Nakahata et $\mathrm{al}^{8}$. The results showed no differences in p values in the cases of IL-3, IL-3 + IL-6, IL-3 + G-CSF and IL-3 + IL-1. To our surprise, p values were narrowly fixed between 0.576 and 0.596 in the presence of one of three synergistic factors. Our hypothesis that synergistic factors could modify both proliferative character and decision-making process to self-renew of hemopoietic stem cells was not deliberate, and then two biological events might be totally different. However, when precisely examined, the colony size distribution of $\mathrm{Bl}$ that could produce $2 \mathrm{nd} \mathrm{Bl}$ progenitors was different between the IL-3 and IL-3 + G-CSF group. The addition of G-CSF produced larger $\mathrm{Bl}$ with an ability to produce 2nd $\mathrm{Bl}$ progenitors. One possibility was that G-CSF kept the self-renewal process of the stem cells for a longer period of cell divisions. Again, there was a difference between IL-3-supported and IL-3 + G-CSFsupported $\mathrm{Bl}$ and the total number of $2 \mathrm{nd} \mathrm{Bl}$ progenitors. The latter produced approximately double the number. This phenomenon might also be ascribed to the above-mentioned possibility.

Many investigators have reported the expansion system of murine and human hemopoietic stem cells using a combination of several cytokines. They documented a large scale expansion judging from the in vitro colony assays, HPP-CFC assay and in vivo CFU-S assay. Bodine et $\mathrm{al}^{3)}$ also reported the hemopoietic stem cell expansion system and they estimated the ratio by use of the in vivo competitive repopulation assay, which was done on day 35 and day 120 after transplantation of the expanded materials. Their data showed that the cytokines like IL-3 + IL-6, IL-3 + G-CSF, IL-4 + IL-6 and IL-3 + G-CSF + IL-6 expanded around 5 times more CFU-S than IL-3 alone after short term liquid cultures. However, according to their competitive repopulation assay, the expanded population stimulated by IL-3 + G-CSF and IL-3 + IL- 6 repopulated around $65 \%$ of the overall hemopoiesis, while the control IL-3-stimulated population occupied $35 \%$, the former having two times more reconstituting ability.

Other expanded population stimulated by IL-3 + G-CSF + IL-6, or IL-4 + IL-6 could occupy only 20 to $30 \%$ of the hemopoiesis. This had not been anticipated. There were differences in the expansion rates of hemopoietic stem cells under the two assay systems, but the competitive repopulation assay has several advantages, such as being an in vivo assay and being able to estimate the long-term-reconstitution ability of stem cells. Their data told us that the short term liquid culture of stem cells in the presence of IL-3 + IL-6 and IL-3 + G-CSF could expand reconstituting stem cells around two fold, which is a similar expansion value to our net product of 2nd Bl progenitors.

To further study the self-renewal process and expansion ratio of the hemopoietic stem 
cells, it is important to establish the exact and short-term-assayable system of the stem cells. Several surface markers have been developed to differentiate immature progenitor cells and stem cells from the majority of mature hemopoietic cells, but it is still difficult to separate stem cells from other progenitor cells. Until we get such special markers, we cannot help depending on the in vitro colony assay and in vivo competitive assay.

We are indebted to Professor M. Honda, Department of Dermatology, and Professor K. Yokomuro, Department of Microbiology and Immunology, Nippon Medical School, for reviewing the manuscript.

\section{References}

1) Haylock, D.N., To., L.B., Dowse, T.L., Juttner, C.A., and Simmons, P.J.: Ex vivo expansion and maturation of peripheral blood CD34 + cells into the myeloid lineage. Blood, 80, 1405 1412, 1992.

2) Koller, M.R., Bender, J.G., Papoutsakis, E.T., and Miller, W.M.: Effects of synergistic cytokine combinations, low oxygen, and irradiated stroma on the expansion of human cord blood progenitors. Blood, 80, 403 411, 1992 .

3) Bodine, D.M., Crosier, P.S., and Clark, S.C.: Effects of hematopoietic growth factors on the survival of primitive stem cells in liquid suspension culture. Blood, 78, 914 920, 1991.

4) Verfaille, C.M.: Soluble factor(s) produced by human bone marrow stroma increase cytokine-induced proliferation and maturation of primitive hematopoietic progenitors while preventing their terminal differentiation. Blood, $\mathbf{8 2}$, 2045 2053, 1993.

5) Ogawa, M.: Differentiation and proliferation of hematopoietic stem cells. Blood, 81, 2844 2853, 1993.

6) Suda, T., Suda, J., and Ogawa, M.: Proliferative kinetics and differentiation of murine blast cell colonies in culture; Evidence for variable Go periods and constant doubling rates of early pluripotent hemopoietic progenitors. J. Cell. Physiol., 117, 308 318, 1983.

7) Nakahata, T., and Ogawa, M.: Identification in culture of a class of hemopoietic colony-forming units with extensive capability to self-renew and generate multipotential hemopoietic colonies. Proc. Natl, Acad. Sci. USA, 79, 3843 3847, 1982 .

8) Nakahata, T., Gross, A.J., and Ogawa, M.: A stochastic model of self-renewal and commitment to differentiation of the primitive hemopoietic stem cells in culture. J. Cell. Physiol., 113, 455 458, 1992.

9) Miyajima, A., Schreurs, A., Otsu, K., Kondo, A., Arai, K., and Maeda, S.: Use of the silkworm, Bombyx mori, and an insect baculovirus vector for high-level expression and secretion of biologically active mouse interleukin-3. Gene, 58, 273 281, 1987.

10) Hirano, T., Yasukawa, K., Harada, H., Taga, H., Watanabe, Y., Matsuda, T., Kashiwamura, S., Nakajima, K., Koyama, K., Iwamatsu, A., Tsunasawa, S., Sakiyama, F., Matsui, H., Takahara, Y., Taniguchi, T., and Kishimoto, T.: Complementary DNA for a novel human interleukin (BSF-2) that induces B lymphocytes to produce immunoglobulin. Nature, 324, 73 76, 1986.

11) Harris, T.E.: Theory of Branching Processes. p. 4 8, RAND corp., Santa Monica, 1964 .

12) Ikebuchi, K., Wong, G.G., Clark, S.C., Ihle, J.N., Hirai, Y., and Ogawa, M.: Interleukin 6 enhancement of interleukin 3-dependent proliferation of multipotential hemopoietic progenitors. Proc. Natl. Acad. Sci. USA, 84, 9035 9039, 1987.

13) Ikebuchi, K., Clark, S.C., Ihle, J.N., Souza, L.M., and Ogawa, M.: Granulocyte colony-stimulating factor enhances interleukin 3-dependent proliferation of multipotential hemopoietic progenitors. Proc. Natl. Acad. Sci. USA, 85, 3445 3449, 1988.

14) Ikebuchi, K, Ihle, J.N., Hirai, Y., Wong, G.G., Clark, S.C., and Ogawa, M.: Synergistic factors for stem cell proliferation; Further studies of the target stem cells and the mechanism of stimulation by interleukin-1, interleukin-6, and granulocyte colony-stimulating factor. Blood 72, 2007 2014, 1988.

15) Leary, A.G., Ikebuchi, K., Hirai, Y., Wong, G.G., Yang, Y.C., Clark, S.C., and Ogawa, M.: Synergism between interleukin- 6 and interleukin-3 in supporting proliferation of human hematopoietic stem cells; Comparison with interleukin-1 $\alpha$. Blood, 71, 1759 1763, 1988 .

16) Musashi, M., Yang, Y.C., Paul, S.R., Clark, S.C., Sudo, T., and Ogawa, M.: Direct and synergistic effects of interleukin-11 on murine hemopoiesis in culture. Proc. Natl. Acad. Sci. USA, 88, 765 769, 1991.

17) Tsuji, K., Zsebo, K.M., and Ogawa, M.: Enhancement of murine blast cell colony formation in culture by recombinant rat stem cell factor, ligand for c-kit. Blood, 78, 1223 1229, 1991.

18) Tsuji, K., Lyman, S.D., Sudo, T., Clark, S.C., and Ogawa, M.: Enhancement of murine hematopoiesis by synergistic interactions between steel factor (ligand for c-kit), interleukin-11, and other eariy acting factors in culture. Blood, 79, 2855 2860, 1992. 